\title{
Twice weekly prophylactic therapy in haemophilia A
}

\author{
A. ARONSTAM ${ }^{1}$, P. J. KIRK, J. MCHARDY, J. W. CULVER-JAMES, \\ D. S. MCLELLAN, P. TURK, S. G. RAINSFORD, AND M. SLATTERY
}

From The Treloar Haemophilia Centre, Lord Mayor Treloar College and Hospital, Alton, Hants

SUMMARY Factor VIII-containing materials were administered to four severely affected haemophiliacs twice weekly in doses calculated to raise the factor VIII level to either $15 \%$ or $30 \%$ of average normal. The pooled results from those patients with statistically similar baseline bleeding frequencies showed a significant reduction in bleeding frequency on both doses in the first 48 hours. The $30 \%$ dose produced a more significant reduction than the $15 \%$ dose in the first 24 hours, but there was no significant difference between the two doses in the second 24 hours. It appears that to reduce the bleeding frequency of severely affected haemophiliacs by $60 \%$ would require a two-and-ahalf-fold increase in therapeutic materials. A $90 \%$ reduction would need nine times the amount of material currently in use.

There have been great advances in the management of haemophiliac bleeds over the past decade but little attention has been paid to their prevention. Conflicting results have been reported in the trials of prophylaxis (Robinson et al., 1967; Nilsson et al., 1970; Ramsay and Parker, 1973). This may have been due in part to the several sources of potential observer and patient bias inherent in any attempt to evaulate such a regime. A double-blind controlled trial of prophylactic treatment has been carried out at the Treloar Haemophilia Centre (Aronstam et al., 1976) where personnel facilities and geographic considerations permit the separation of clinical management and trial administration. The weekly administration of factor VIIl-containing material calculated to raise the factor VIII level to $0.25 \mathrm{IU} / \mathrm{ml}(25 \%$ of average normal) reduced the overall bleeding frequency in nine severe haemophiliacs by $15 \%$. Analysis of the results on each individual day after a prophylactic dose showed a two-thirds reduction of bleeding frequency over the first two and one-third days. It was calculated that a two-and-a-half-fold increase in therapeutic materials would be needed to achieve this substantial reduction in bleeding frequency.

In view of the implications for the limited financial and human resources available to service such a commitment, it is important to confirm these findings and to establish the lowest dose which might be

\footnotetext{
${ }^{1}$ Present address: Department of Medicine, Victoria Hospital, London, Ontario N6A 4G5, Canada

Received for publication 24 May 1976
}

beneficial. The work reported here is a step along that path.

\section{Material and methods}

The Treloar Haemophilia Centre includes the Lord Mayor Treloar College, the coagulation laboratory at the Lord Mayor Treloar Hospital, which is five miles from the College, and the haemophilia ward at the hospital. The Lord Mayor Treloar College is a school for disabled children: 50 of the pupils are haemophiliacs. Clinical management of the boys on the trial was shared between the College Medical Officer (JMcH), a Research Senior Registrar (PJK), and an SHO (JC-J). These were at all times blind to the particular trial dosage of the different boys, although they were aware that any given boy was on the trial. Diagnosis of a bleeding episode requiring treatment was made at the College. Routine treatment was given at either the College or the haemophilia ward at the hospital and prophylactic treatment was given at the hospital. The majority of these infusions were given by one of us (PT) and none was given by any of the doctors designated above.

\section{SELECTION OF CASES}

Those boys who had been on the first double-blind controlled trial (Aronstam et al., 1976) and were still available for a further two terms were selected. There were four such boys, patients $1,3,8$, and 9 of that trial. The boys selected had each had at least one 
full school term off prophylaxis before entering the second trial.

All the cases suffered from classical haemophilia and had no detectable factor VIII in their plasma. During their stay at the College, while not on prophylaxis, their baseline bleeding frequencies were observed to be $14.6,18 \cdot 3,15 \cdot 3$, and 13.1 bleeds per 100 days (mean 15.3). A bleeding episode was defined as any discrete episode of muscle, joint, subcutaneous, genitourinary, or nasal haemorrhage which required treatment with a factor VIII-containing material.

\section{TRIAL DESIGN}

Twice-weekly infusions of factor VIII-containing material, calculated to raise the boys' factor VIII levels to either $15 \%$ or $30 \%$ of average normal, were given. The material given was either cryoprecipitate, prepared by the Wessex Regional Transfusion Centre, or a factor VIII concentrate marketed by Serological Products Ltd (Kryobulin). The boys were allocated to different treatment schedules at random at the start of the trial and the dose schedules were reversed during the second term.

At the beginning of each trial term screening for inhibitors to factor VIII and hepatitis B surface antigen (HBsAg) was carried out. During each trial term the response to the prophylactic material was tested on each boy on two separate occasions.

\section{ADMINISTRATION OF PROPHYLACTIC \\ MATERIALS}

This was carried out on Monday and Thursday afternoons at about 1600 hours so as to interfere as little as possible with the boys' schooling and leisure. The boys were not aware that there was any difference in dose schedules over the two terms. A bleeding episode occurring on the day of the scheduled dose was treated in the standard way with a dose of therapeutic material 'topped up' to the trial dosage level if necessary.

\section{LABORATORY METHODS}

Factor VIII assays, inhibitor screens, and tests for HBsAg were carried out as previously described (Aronstam et al., 1976).

\section{PROPHYLACTIC MATERIALS}

The strength of the cryoprecipitate used at our centre is constantly monitored. The strength of each preparation of Kryobulin is recorded on the pack, and our own random assays confirmed these.

\section{Results}

Eighty-three infusions of high-dose material and 71
Table 1 Number of infusions given to raise the factor VIII level to $15 \%$ or $30 \%$

\begin{tabular}{|c|c|c|}
\hline Case & Infusions to $15 \%$ & Infusions to $30 \%$ \\
\hline $\begin{array}{l}1 \\
2 \\
3 \\
4\end{array}$ & $\begin{array}{l}24 \\
21 \\
16 \\
22\end{array}$ & $\begin{array}{l}17 \\
13 \\
22 \\
19\end{array}$ \\
\hline
\end{tabular}

Table 2 Bleeds on each individual day after a prophylactic dose raising the fVIII level to $15 \%$ or $30 \%$

\begin{tabular}{|c|c|c|c|c|c|c|}
\hline \multirow[t]{2}{*}{ Case } & \multicolumn{3}{|l|}{$15 \%$} & \multicolumn{3}{|l|}{$30 \%$} \\
\hline & Day 1 & Day 2 & Day 3 & Day 1 & Day 2 & Day 3 \\
\hline 1 & 3 & 2 & 1 & 1 & 2 & 1 \\
\hline 2 & 1 & 6 & 1 & 1 & 2 & 3 \\
\hline 3 & 0 & 0 & 3 & 0 & 1 & 4 \\
\hline 4 & 1 & 2 & 3 & 0 & 0 & 0 \\
\hline
\end{tabular}

Table 3 Bleeds per 100 days observed on each individuat day after a prophylactic dose raising the fVIII level to $15 \%$ or $30 \%$

\begin{tabular}{|c|c|c|c|c|c|c|c|}
\hline \multirow[t]{2}{*}{ Case } & \multirow[t]{2}{*}{ Baseline } & \multicolumn{3}{|l|}{$15 \%$} & \multicolumn{3}{|l|}{$30 \%$} \\
\hline & & $\begin{array}{l}\text { Day } \\
1\end{array}$ & $\begin{array}{l}\text { Day } \\
2\end{array}$ & $\begin{array}{l}\text { Day } \\
3\end{array}$ & $\begin{array}{l}\text { Day } \\
1\end{array}$ & $\begin{array}{l}\text { Day } \\
2\end{array}$ & $\begin{array}{l}\text { Day } \\
3\end{array}$ \\
\hline $\begin{array}{l}1 \\
2 \\
3 \\
4\end{array}$ & $\begin{array}{l}14 \cdot 6 \\
18 \cdot 3 \\
15 \cdot 3 \\
13 \cdot 1\end{array}$ & $\begin{array}{c}12 \cdot 5 \\
4 \cdot 8 \\
0 \\
4 \cdot 5\end{array}$ & $\begin{array}{c}8 \cdot 3 \\
28 \cdot 6 \\
0 \\
9 \cdot 1\end{array}$ & $\begin{array}{r}4 \cdot 2 \\
4 \cdot 8 \\
18 \cdot 8 \\
13.6\end{array}$ & $\begin{array}{l}5 \cdot 9 \\
7 \cdot 7 \\
0 \\
0\end{array}$ & $\begin{array}{c}11.8 \\
15.4 \\
4.5 \\
0\end{array}$ & $\begin{array}{c}5 \cdot 9 \\
23 \cdot 1 \\
18 \cdot 2 \\
0\end{array}$ \\
\hline
\end{tabular}

of low-dose material were given to the four boys on the trial over the two school terms. The number of infusions given to each individual boy is shown in? Table 1. The number of bleeds on each individuap़ day after an infusion is shown in Table 2. It is possible to calculate the percentage bleeding fre? quency from the data in Tables 1 and 2 , and the result of these calculations is shown in Table 3. In no. case did any boy show a significant departure from? baseline bleeding frequencies on any individual day.

The individual boys were compared by their base-line bleeding frequency. It emerged that boy $1(14.6$ bleeds per 100 days), boy $3(15.3$ bleeds per $100 \mathrm{E}$. days), and boy 4 (13.5 bleeds per 100 days) were no statistically different from each other when tested by a binomial test on their respective number of observed days. We therefore pooled boys 1, 3, andw 4 and took the average which was obtained by add $₹$ ing all their days of observation and all their bleedinge episodes for separate days 1,2 , and 3, following either a $15 \%$ or a $30 \%$ dose. The baseline bleeding frequency for this group was 14.5 bleeds per 100 days and the average percentage of bleeding fre $-\frac{O}{\mathrm{D}}$ quencies is shown in Table 4 , together with the? significance of the drop in bleeding frequencies froma the baseline. The $30 \%$ dose produced a more signific cant reduction in bleeding frequencies $(P<0.01) \%$ 
Table 4 Average of boys 1,3, and 4: percentage of bleeding frequencies and significance of the drop in bleeding frequency from baseline (14.5\%)

\begin{tabular}{lllll}
\hline Day & $15 \%$ Dose & Significance & $30 \%$ Dose & Significance \\
\hline 1 & 6.2 & 0.05 & 1.7 & 0.01 \\
2 & 6.2 & 0.05 & 5.2 & 0.05 \\
3 & 11.3 & N/S & 9.6 & N/S \\
\hline
\end{tabular}

than the $15 \%$ dose $(P<0.05)$ on the first day, but reductions were equally significant on day 2 $(P<0.05)$. There was no significant reduction on day 3 .

\section{DEVELOPMENT OF INHIBITORS}

No case developed during the trial.

\section{HEPATITIS}

No case developed during the trial.

\section{FACTOR VIII ASSAYS}

The factor VIII levels achieved after a prophylactic dose were assayed on two occasions on each boy during each term. The mean of the eight assays done on the high-dose schedule, expressed as a percentage of average normal, was $28 \cdot 37 \pm 3 \cdot 50$. The mean of the eight assays done on the low-dose schedule was $16.94 \pm 3 \cdot 82$.

\section{Discussion}

Our results demonstrate an initial superiority of the $30 \%$ dose which rapidly returns to the same level as the $15 \%$ dose, and neither dose seems to have any major effectiveness after the second day. This broadly confirms the results of our last trial in which no significant effect could be demonstrated after two-and-a-third days. It appears therefore that a reduction in bleeding frequency of about $60 \%$ can be achieved by raising the factor VIII level to $15 \%$ every 48 hours. The standard therapy for a spontaneous bleed is to raise the factor VIII level to $20 \%$ (Rizza, 1972), and in our experience 1.2 standard doses are needed to treat each spontaneous bleeding episode (Rainsford and Hall, 1973). The average baseline bleeding frequency of 14.5 bleeds per 100 days would therefore need 17.4 standard doses in 100 days. The prophylactic dose regime mentioned above would reduce the bleeding frequency by $60 \%$ to 5.8 bleeds per 100 days, requiring seven standard doses in 100 days to treat those bleeds. In addition, prophylaxis every 48 hours would require 50 doses of material calculated to raise the factor VIII level to $15 \%$, or the equivalent of 37.5 standard doses. This, together with the seven standard doses required to treat the reduced bleeding frequency, makes a total of 44.5 standard doses in 100 days. A two-and-a-halffold increase in therapeutic materials would therefore be needed to reduce the bleeding frequency by $60 \%$. This conclusion agrees substantially with our earlier work.

From the data presented it might reasonably be concluded that the 24-hourly prophylactic administration of a dose of factor VIII, calculated to raise the level to $30 \%$, would reduce the bleeding frequency by $90 \%$. The application of a similar calculation to that explained above suggests that such a commitment would need nearly nine times the amount of therapeutic material currently in use for haemophiliacs with comparable bleeding frequencies.

Clearly, this sort of commitment is not possible with known therapeutic materials, given the current limitations of human and financial resources, particularly in the UK. Indeed, the two-and-a-half-fold increase in therapeutic materials needed to reduce the bleeding frequency by $60 \%$ is not within our compass. We feel that further work in this field should be directed towards the possible benefits of limited periods of prophylaxis. The possibility that a badly affected joint might improve on short-term prophylaxis and reduce the bleeding frequency in the long term appears the most fruitful line to be evaluated at the present time.

Dr Kirk's work was supported in part by the Sir William Coxon Trust and the Lord Mayor Treloar Trust.

\section{References}

Aronstam, A., Arblaster, P. G., Rainsford, S. G., Turk, P., Slattery, M., Alderson, M. R., Hall, D. E., and Kirk, P. J. (1976). Prophylaxis in haemophilia: a double-blind controlled trial. British Journal of Haematology, 33, 81-90.

Nilsson, I. M., Blombäck, M., and Ahlberg, Ä. (1970). Our experience in Sweden with prophylaxis in haemophilia. Bibliotheca Haematologica, 34, 111-124.

Rainsford, S. G. and Hall, A. (1973). A three-year study of adolescent boys suffering from haemophilia and allied disorders. British Journal of Haematology, 24, 539-551.

Ramsay, D. M. and Parker, A. C. (1973). A trial of prophylactic replacement therapy in haemophilia and Christmas disease. Journal of Clinical Pathology, 26, 243247.

Rizza, C. R. (1972). The management of patients with coagulation factor dificiencies. In Human Blood Coagulation, Haemostasis and Thrombosis, edited by R. Biggs, pp. 336360. Blackwell, Oxford.

Robinson, P. M., Tittley, P., and Smiley, R. K. (1967). Prophylactic therapy in classical hemophilia: a preliminary report. Canadian Medical Association Journal, 97, 559-561. 